\title{
Occurrence of parasitoids of the family Ichneumonidae (Hymenoptera) in the Botanical Garden of the Adam Mickiewicz University in Poznań
}

\author{
Występowanie parazytoidów z rodziny gąsienicznikowatych (Hymenoptera, \\ Ichneumonidae) w Ogrodzie Botanicznym Uniwersytetu \\ im. Adama Mickiewicza w Poznaniu
}

\author{
Marta Rzańska*, Hanna Piekarska-Boniecka, Paweł Trzciński
}

\begin{abstract}
Summary
The study was conducted at the Botanical Garden of Adam Mickiewicz University in Poznan in 2007-2009. The aim of the study was to investigate the quality and quantity structure of the Pimplinae parasitoids of the selected subfamily Ichneumonidae, which colonize plants growing in this area. The study used the method of trapping adults of parasitoids to yellow Moericke's traps. A total of 748 samples were collected. The results showed that 130 individuals of Ichneumonidae belonging to 31 species were caught. The occurrence of 29 species belonging to the subfamily Pimplinae and one species of the subfamily Poemeniinae and Rhyssinae was confirmed. Pimpla contemplator (Muell.) (31,2\%), Zaglyptus multicolor (Grav.) (8,0\%), Itoplectis maculator (F.) $(5,6 \%)$ and P. flavicoxis (Thoms.) (5,6\%) were counted as the dominant species of this subfamily. The performed studies have demonstrated that urban green spaces are readily colonized by parasitoids, which have a significant impact on the health status of the plants because they limit the number of pests that feed on plants.
\end{abstract}

Key words: Ichneumonidae; parasitoids; pests of plants; Pimplinae; Poznań; urban greenery

\section{Streszczenie}

Badania prowadzone były w latach 2007-2009 na terenie Ogrodu Botanicznego Uniwersytetu im. Adama Mickiewicza w Poznaniu. Ich celem było poznanie struktury jakościowo-ilościowej zgrupowań parazytoidów z wybranych podrodzin Ichneumonidae, zasiedlających rośliny rosnące na tym terenie. W badaniach wykorzystano metodę odłowu imagines parazytoidów do żółtych pułapek Moerickego. W latach 2007-2009 w Ogrodzie Botanicznym pobrano 748 prób. Odłowiono 130 osobników Ichneumonidae oznaczonych do 31 gatunków. Stwierdzono występowanie 29 gatunków należących do podrodziny Pimplinae oraz po jednym gatunku z podrodziny Poemeniinae i Rhyssinae. Dominującymi gatunkami w najliczniejszej z podrodzin okazały się: Pimpla contemplator (Muell.) (31,2\%), Zaglyptus multicolor (Grav.) (8,0\%), Itoplectis maculator (F.) (5,6\%) oraz P. flavicoxis (Thoms.) (5,6\%). Prowadzone badania wykazały, że tereny zieleni miejskiej są chętnie zasiedlane przez parazytoidy, które w znaczący sposób wpływają na stan zdrowotny roślin, ponieważ ograniczają liczebność żerujących na nich szkodników roślin.

Słowa kluczowe: Ichneumonidae; parazytoidy; szkodniki roślin; Pimplinae; Poznań; zieleń miejska

Uniwersytet Przyrodniczy w Poznaniu

Katedra Entomologii i Ochrony Środowiska

Wojska Polskiego 28, 60-637 Poznań

*corresponding author: mrzanska@up.poznan.pl 


\section{Wstęp / Introduction}

Tereny zieleni miejskiej spełniają funkcje rekreacyjne, estetyczne i edukacyjne. Służą także zachowaniu bioróżnorodności. Powinny zatem odznaczać się dużym wigorem, zdrowotnością i dekoracyjnością oraz brakiem symptomów chorób i uszkodzeń powodowanych przez owady. Duża różnorodność gatunkowa drzew i krzewów sadzonych w miastach stwarza korzystne warunki dla rozwoju żerujących na nich szkodników (Tomalak 2003).

Wśród owadów występujących w terenach zieleni miejskiej są także entomofagiczne błonkówki, do których zalicza się parazytoidy $\mathrm{z}$ rodziny gąsienicznikowatych (Hymenoptera, Ichneumonidae) (Sawoniewicz 1982, 1986; Piekarska-Boniecka 2004; Piekarska-Boniecka i wsp. 2009a, b), które stanowią ważną grupę organizmów regulujących liczebność gatunków fitofagicznych zasiedlających roślinność miejską. Owady do niej należące to parazytoidy wielu gatunków roślinożernych: Lepidoptera, Coleoptera, Hymenoptera i Diptera, korzystnie wpływające na zdrowotność rosnących tam roślin.

Niewiele jest polskich i światowych opracowań dotyczących występowania parazytoidów z rodziny Ichneumonidae w środowiskach zieleni miejskiej. Dotychczas badania dotyczace tej tematyki prowadzili jedynie Sawoniewicz w Warszawie (Sawoniewicz 1982, 1986) oraz Piekarska-Boniecka w Poznaniu i Kórniku (Piekarska-Boniecka 2004; Piekarska-Boniecka i wsp. 2009a, b). W Bułgarii badania nad parazytoidami występującymi w zieleni miejskiej prowadził Georgiev (2000), a w Japonii Minami i wsp. (1999).

Podjęto badania, których celem było poznanie struktury jakościowo-ilościowej zgrupowań parazytoidów z wybranych podrodzin Ichneumonidae zasiedlających roślinność Ogrodu Botanicznego im. Uniwersytetu Adama Mickiewicza, który jest jednym z większych terenów zieleni miejskiej Poznania.

\section{Materiały i metody / Materials and methods}

Badania nad występowaniem parazytoidów z wybranych podrodzin Ichneumonidae prowadzono w latach 2007-2009 na terenie Ogrodu Botanicznego Uniwersytetu im. Adama Mickiewicza w Poznaniu, usytuowanego w zachodniej części miasta, w dzielnicy Jeżyce. Jego położenie geograficzne wyznaczają współrzędne $52^{\circ} 25^{\prime} \mathrm{N}$ i $16^{\circ} 53^{\prime}$ E. Ogród Botaniczny zajmuje powierzchnię 22 ha, na której rośnie ponad 8000 gatunków roślin. Podzielony jest na kilka działów. Badania prowadzone były w 4 następujących działach: ekologiczno-geograficznym o powierzchni 6,7 ha, roślin ozdobnych o powierzchni 1 ha, rzadkich i ginących o powierzchni 0,5 ha oraz kolekcji dendrologicznych zajmujących 3,8 ha. Dział roślin ozdobnych graniczy $\mathrm{z}$ działami ekologiczno-geograficznym i kolekcji dendrologicznych, które równocześnie przylegają do działu roślin rzadkich i ginących.

Dział ekologiczno-geograficzny zawiera fragment lasu dębowo-grabowego (Galio sylvatici-Carpinetum) (R. Tx. 1937) Oberd. 1957 oraz kompleks szuwarowo-łąkowy, reprezentowany głównie przez gatunki charakterystyczne dla dwóch klas zbiorowisk, a mianowicie bagienne z Phragmitetea i łąkowe z Molinio-Arrhenatheretea. Bogata kolekcja roślin jednorocznych, dwuletnich, wieloletnich oraz traw i turzyc tworzy dział roślin ozdobnych m.in. z rodzin: astrowatych (Asteraceae), goździkowatych (Caryophyllaceae), różowatych (Rosaceae), wiechlinowatych (Poaceae) i ciborowatych (Cyperaceae). Szczególnie dużym zainteresowaniem cieszą się kwitnące wiosną liliowate (Liliaceae) oraz stanowiące ozdobę ogrodu przez wiele miesięcy żółtakowate (Xanthorrhoeaceae). W dziale roślin rzadkich $\mathrm{i}$ ginących rosną m.in. rośliny $\mathrm{z}$ rodzin: astrowatych (Asteraceae), selerowatych (Apiaceae) i jaskrowatych (Ranunculaceae). Do kolekcji dendrologicznych zalicza się teren $\mathrm{z}$ drzewami należącymi do rodzin cyprysowatych (Cupressaceae) i sosnowatych (Pinaceae) oraz obszar obsadzony wieloma gatunkami krzewów ozdobnych $\mathrm{z}$ rodzin: berberysowatych (Berberidaceae), dereniowatych (Cornaceae), nanerczowatych (Anacardiaceae) czy oliwkowatych (Oleaceae).

$\mathrm{W}$ badaniach wykorzystano metodę odłowu imagines parazytoidów do żółtych pułapek Moerickego. Na terenie ogrodu umieszczono 10 takich pułapek w odległości około $100 \mathrm{~m}$ każda od siebie, zawieszonych około $1,5 \mathrm{~m}$ od powierzchni ziemi. Pułapki lokalizowano w miejscach o wysokim nasłonecznieniu tak, by jednocześnie były osłonięte od wiatru. W działach roślin ozdobnych oraz rzadkich i ginących umieszczono po 2 pułapki, natomiast w pozostałych działach po 3 pułapki.

Warunki pogodowe występujące w latach 2007-2009 były do siebie bardzo zbliżone.

Odłowy prowadzono od 1 kwietnia do 31 października każdego roku, a próby pozyskiwano w odstępach dekadowych. W okresie prowadzenia badań nie stosowano środków ochrony roślin.

\section{Wyniki i dyskusja / Results and discussion}

W latach 2007-2009 z terenu Ogrodu Botanicznego pobrano łącznie 748 prób. Odłowiono 130 osobników gąsienicznikowatych należących do 31 gatunków (tab. 1). Najliczniej reprezentowana okazała się podrodzina Pimplinae, do której zaliczono 29 gatunków (125 osobników). Stwierdzono także jeden gatunek $\mathrm{z}$ podrodziny Poemeniinae (Poemenia collaris) oraz jeden $\mathrm{z}$ podrodziny Rhyssinae (Rhyssella obliterata). Odłowione gatunki Pimplinae stanowiły 21,0\% wykazanych dotychczas z Polski (Bogdanowicz i wsp. 2007) oraz 37,2\% z Wielkopolski (Szulczewski 1939; Bałazy i wsp. 1979; Bałazy i Michalski 1983; Piekarska-Boniecka 2005, 2009a, b). Wśród przedstawicieli Pimplinae pojawił się jeden eudominant i był nim Pimpla contemplator (31,2\%). Do dominantów należały Zaglyptus multicolor (8,0\%), Itoplectis maculator (5,6\%) oraz P. flavicoxis $(5,6 \%)$ (tab. 1$)$.

Analiza odłowu gąsienicznikowatych do poszczególnych pułapek Moerickego, umieszczonych w badanych działach wykazała, że zgrupowanie parazytoidów w kolekcji roślin ozdobnych charakteryzowało się największą liczebnością i zróżnicowaniem gatunkowym (tab. 2). W dziale tym odłowiono 62 osobniki należące do 25 gatunków. Drugim z działów Ogrodu Botanicznego, wyróż- 
niającym się pod względem struktury jakościowo-ilościowej odłowionych parazytoidów, okazał się dział ekologiczno-geograficzny. Zgrupowanie Ichneumonidae odłowione w tej części ogrodu liczyło 41 osobników należących do 16 gatunków. W pozostałych działach, czyli roślin rzadkich i ginących oraz kolekcji dendrologicznych, stwierdzono zgrupowania gąsienicznikowanych o znacznie niższej liczebności oraz mniejszej liczbie gatunków, liczebności i zróżnicowanie gatunkowe było zbliżone.
Najbardziej rozbudowane w swojej strukturze jakościowo-ilościowej zgrupowanie parazytoidów $\mathrm{z}$ rodziny Ichneumonidae wystąpiło $\mathrm{w}$ dziale roślin ozdobnych, co może wskazywać na fakt, iż gąsienicznikowate prefeują jednoroczne i wieloletnie rośliny ozdobne, które zwabiają owady mozaiką różnorodnych barw, form kwitnienia czy uwalnaniem soków i nektarów stanowiących źródło ich pożywienia (Kaźmierczakowa i wsp. 1997; Kaźmierczak 2010) (tab. 2).

Tabela 1. Wykaz gatunków Ichneumonidae odłowionych w Ogrodzie Botanicznym Uniwersytetu im. Adama Mickiewicza w Poznaniu w latach 2007-2009

Table 1. List of Ichneumonidae species caught at the Botanical Garden of Adam Mickiewicz University in 2007-2009

\begin{tabular}{|c|c|c|c|c|}
\hline \multirow{2}{*}{$\begin{array}{l}\text { Gatunek } \\
\text { Species }\end{array}$} & \multicolumn{4}{|c|}{$\begin{array}{c}\text { Liczba osobników } \\
\text { Number of specimens }\end{array}$} \\
\hline & 2007 & 2008 & 2009 & $2007-2009$ \\
\hline \multicolumn{5}{|c|}{ Pimplinae } \\
\hline Acropimpla pictipes (Gravenhorst, 1829) & - & 2 & - & 2 \\
\hline Apechthis quadridentata (Thomson, 1877) & - & 2 & - & 2 \\
\hline Clistopyga incitator (Fabricius, 1793) & 1 & 1 & 1 & 3 \\
\hline Delomerista mandibularis (Gravenhorst, 1829) & - & 3 & 3 & 6 \\
\hline Dolichomitus pterelas (Say, 1829) & - & 1 & - & 1 \\
\hline Ephialtes manifestator (Linnaeus, 1758) & - & - & 1 & 1 \\
\hline Endromopoda detrita (Holmgren, 1860) & - & 2 & - & 2 \\
\hline Gregopimpla inquisitor (Scopoli, 1763) & 1 & 1 & 1 & 3 \\
\hline Itoplectis alternans (Gravenhorst, 1829) & 3 & - & 1 & 4 \\
\hline I. maculator (Fabricius, 1775) & 2 & 1 & 4 & 7 \\
\hline Liotryphon caudatus (Ratzeburg, 1848) & 4 & - & - & 4 \\
\hline L. crassiseta (Thomson, 1877) & - & 1 & 1 & 2 \\
\hline L. punctulatus (Ratzeburg, 1848) & - & 1 & 1 & 2 \\
\hline Perithous divinator (Rossi, 1790) & - & 1 & 1 & 2 \\
\hline Pimpla contemplator (Muller, 1776) & 4 & 12 & 23 & 39 \\
\hline P. flavicoxis Thomson, 1877 & - & 3 & 4 & 7 \\
\hline P. insignatoria (Gravenhorst, 1807) & - & 1 & 1 & 2 \\
\hline P. rufipes (Miller, 1759) & 1 & 1 & - & 2 \\
\hline P. spuria Gravenhorst, 1829 & - & 1 & - & 1 \\
\hline P. turionellae Linnaeus, 1758 & 1 & 1 & 2 & 4 \\
\hline Scambus inanis (Schrank, 1802) & - & - & 5 & 5 \\
\hline S. brevicornis (Gravenhorst, 1829) & - & - & 1 & 1 \\
\hline S. elegans (Woldstedt, 1877) & - & 1 & - & 1 \\
\hline S. nigricans (Thomson, 1877) & - & 1 & 1 & 2 \\
\hline Schizopyga circulator (Panzer, 1800) & - & 1 & - & 1 \\
\hline Tromatobia lineatoria (Villers, 1789) & - & 2 & - & 2 \\
\hline Zaglyptus multicolor (Gravenhorst, 1829) & 1 & 5 & 4 & 10 \\
\hline Zatypota eximia (Schmiedeknecht, 1907) & - & 1 & 1 & 2 \\
\hline Z. percontatoria (Muller, 1776) & 1 & 3 & 1 & 5 \\
\hline \multicolumn{5}{|c|}{ Poemeniinae } \\
\hline Poemenia collaris (Haupt, 1917) & - & 3 & - & 3 \\
\hline \multicolumn{5}{|c|}{ Rhyssinae } \\
\hline Rhyssella obliterata (Gravenhorst, 1829) & - & 2 & - & 2 \\
\hline $\begin{array}{l}\text { Ogółem } \\
\text { Total }\end{array}$ & 19 & 54 & 57 & 130 \\
\hline
\end{tabular}


Tabela 2. Wykaz gatunków Ichneumonidae odłowionych w poszczególnych działach Ogrodu Botanicznego Uniwersytetu im. Adama Mickiewicza w Poznaniu łącznie w latach 2007-2009: a - roślin ozdobnych, b - rzadkich i ginących, c - kolekcji dendrologicznych, $\mathrm{d}$ - ekologiczno-geograficzny

Table 2. List of Ichneumonidae species caught in the specific sections at the Botanical Garden of Adam Mickiewicz University in Poznań in the years from 2007 to 2009: a - ornamental plants, b - rare and endangered plants, c - dendrological collection, $\mathrm{d}$ - ecological and geographical

\begin{tabular}{|c|c|c|c|c|c|c|c|c|c|c|c|}
\hline \multirow{3}{*}{ Gatunek - Species } & \multicolumn{10}{|c|}{ Działy - Sections } & \multirow{3}{*}{$\begin{array}{l}\text { Ogółem } \\
\text { Total }\end{array}$} \\
\hline & \multicolumn{2}{|c|}{ a } & \multicolumn{2}{|c|}{$\mathrm{b}$} & \multicolumn{3}{|c|}{$\mathrm{c}$} & \multicolumn{3}{|c|}{$\mathrm{d}$} & \\
\hline & $\mathrm{P} 1 *$ & $\mathrm{P} 2$ & P3 & $\mathrm{P} 4$ & P5 & P6 & $\mathrm{P} 7$ & P8 & P9 & $\mathrm{P} 10$ & \\
\hline Acropimpla pictipes (Grav.) & 1 & - & - & - & - & - & - & 1 & - & - & 2 \\
\hline Apechthis quadridentata (Thoms.) & - & - & - & - & - & - & - & - & 1 & 1 & 2 \\
\hline Clistopyga incitator $(\mathrm{F})$. & 2 & - & - & - & - & 1 & - & - & - & - & 3 \\
\hline Delomerista mandibularis (Grav.) & - & 1 & - & 1 & 1 & - & - & 3 & - & - & 6 \\
\hline Dolichomitus pterelas (Say) & - & - & - & - & - & - & - & 1 & - & - & 1 \\
\hline Ephialtes manifestator (L.) & - & - & - & - & - & - & - & - & - & 1 & 1 \\
\hline Endromopoda detrita (Holmgr.) & 2 & - & - & - & - & - & - & - & - & - & 2 \\
\hline Gregopimpla inquisitor (Scop.) & 1 & 1 & - & - & - & - & - & - & 1 & - & 3 \\
\hline Itoplectis alternans (Grav.) & 2 & 1 & - & 1 & - & - & - & - & - & - & 4 \\
\hline I. maculator (F.) & 3 & 2 & - & - & 1 & 1 & - & - & - & - & 7 \\
\hline Liotryphon caudatus (Ratz.) & 2 & 2 & - & - & - & - & - & - & - & - & 4 \\
\hline L. crassiseta (Thoms.) & 1 & 1 & - & - & - & - & - & - & - & - & 2 \\
\hline L. punctulatus (Ratz.) & - & - & - & - & - & - & 1 & 1 & - & - & 2 \\
\hline Perithous divinator (Rossi) & - & 1 & - & 1 & - & - & - & - & - & - & 2 \\
\hline Pimpla contemplator (Muell.) & 8 & 9 & 1 & 8 & 1 & - & - & 6 & 4 & 2 & 39 \\
\hline P. flavicoxis Thoms & 2 & - & - & - & - & - & - & 1 & 3 & 1 & 7 \\
\hline P. insignatoria (Grav.) & - & - & - & 1 & - & - & - & 1 & - & - & 2 \\
\hline P. rufipes (Mill.) & - & 1 & - & - & - & - & - & - & - & 1 & 2 \\
\hline P. spuria Grav. & - & 1 & - & - & - & - & - & - & - & - & 1 \\
\hline P. turionellae $\mathrm{L}$. & 1 & - & - & - & 1 & - & - & - & 1 & 1 & 4 \\
\hline Scambus inanis (Schrank) & 3 & 2 & - & - & - & - & - & - & - & - & 5 \\
\hline S. brevicornis (Grav.) & - & - & - & - & - & 1 & - & - & - & - & 1 \\
\hline S. elegans (Woldst.) & - & 1 & - & - & - & - & - & - & - & - & 1 \\
\hline S. nigricans (Thoms) & 1 & - & - & - & - & - & 1 & - & - & - & 2 \\
\hline Schizopyga circulator (Panzer) & - & 1 & - & - & - & - & - & - & - & - & 1 \\
\hline Tromatobia lineatoria (Vill.) & 1 & - & - & - & - & - & - & 1 & - & - & 2 \\
\hline Zaglyptus multicolor (Grav.) & 1 & 2 & 1 & - & 1 & - & - & - & 3 & 2 & 10 \\
\hline Zatypota eximia (Schmied.) & 1 & - & - & - & - & - & - & 1 & - & - & 2 \\
\hline Z. percontatoria (Muell.) & 1 & 1 & - & - & - & - & - & 1 & 2 & - & 5 \\
\hline Poemenia collaris (Haupt) & - & 1 & 1 & 1 & - & - & - & - & - & - & 3 \\
\hline Rhyssella obliterata (Grav.) & 1 & - & - & - & - & 1 & - & - & - & - & 2 \\
\hline $\begin{array}{l}\text { Liczba osobników ogółem } \\
\text { Total number of specimens }\end{array}$ & 34 & 28 & 3 & 13 & 5 & 4 & 2 & 17 & 15 & 9 & 130 \\
\hline $\begin{array}{l}\text { Liczba osobników w danym dziale } \\
\text { The number of specimens per section }\end{array}$ & \multicolumn{2}{|c|}{62} & \multicolumn{2}{|c|}{16} & \multicolumn{3}{|c|}{11} & \multicolumn{3}{|c|}{41} & 100 \\
\hline $\begin{array}{l}\text { Liczba gatunków ogółem } \\
\text { Total number of species }\end{array}$ & 18 & 16 & 3 & 6 & 5 & 4 & 2 & 10 & 7 & 7 & 31 \\
\hline $\begin{array}{l}\text { Liczba gatunków } \mathrm{w} \text { danym dziale } \\
\text { The number of species per section }\end{array}$ & \multicolumn{2}{|c|}{25} & \multicolumn{2}{|c|}{7} & \multicolumn{3}{|c|}{10} & \multicolumn{3}{|c|}{16} & J1 \\
\hline
\end{tabular}

*numer pułapki - trap number

Dominujące gatunki Pimplinae, z wyjątkiem Z. multicolor, są poczwarkowymi endoparazytoidami szkodników roślin z rzędów: Lepidoptera, Coleoptera, Hymenoptera i Diptera. Z. multicolor należy do ektoparazytoidów doros- 
łych Arachnida. Przedstawiciel Poemeniinae - P. collaris jest larwalnym ektoparazytoidem ksylofagicznych Coleoptera. Gatunek $R$. obliterata należy do larwalnych ektoparazytoidów ksylofagicznych Hymenoptera (Yu i Horstmann 1997; Yu 2012).

Wśród wszystkich odłowionych w Ogrodzie Botanicznym w latach 2007-2009 gatunków Ichneumonidae dominowały parazytoidy fitofagów (rys. 1). Należały do nich aż 24 gatunki (78\%), które zaliczono do rodzajów: Acropimpla, Apechthis, Delomerista, Ephialtes, Endromopoda, Gregopimpla, Itoplectis, Liotryphon, Pimpla, Scambus oraz Poemenia i Rhyssella. Drugą, znacznie mniej liczną grupę (19\%), stanowiły parazytoidy Arachnida, należące do rodzajów: Clistopyga, Schizopyga, Tromatobia, Zaglyptus i Zatypota. Jedynym przedstawicielem parazytoidów Aculeata okazał się Perithous divinator ( $\mathrm{Yu}$ i Horstmann 1997; Yu 2012) (rys. 1).

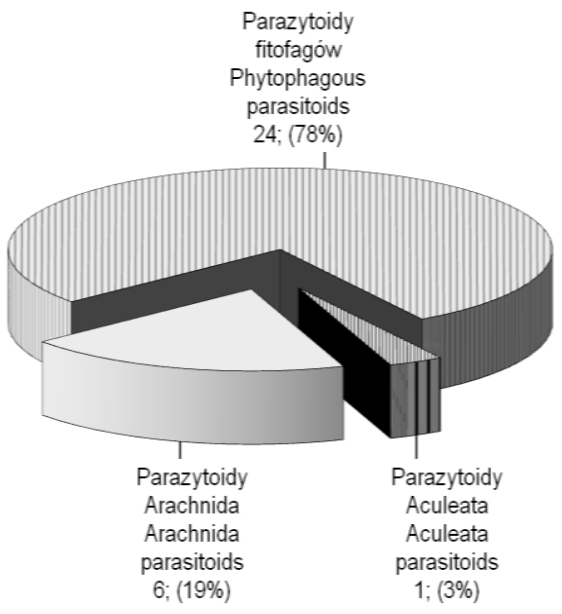

Rys. 1. Powiązania troficzne gatunków z rodziny Ichneumonidae

Fig. 1. Trophic relationships of species of the family Ichneumonidae
Z przeprowadzonych badań wynika, że większość odłowionych gatunków to polifagi należące do rodzajów: Apechthis, Gregopimpla, Itoplectis, Pimpla i Scambus, które mogą w znacznym stopniu ograniczać liczebność groźnych szkodników, żerujących na roślinach powszechnie występujących w terenach zieleni miejskiej. Parazytoidy z rodzaju Apechthis mogą pasożytować takie szkodniki, jak: Archips rosana, Malacosoma neustria czy Diprion pini. Polifagi z rodzaju Gregopimpla, Itoplectis i Pimpla mogą regulować liczebność groźnych fitofagów, jakimi są m.in.: Lymantria dispar, Euproctis chrysorrhoea, Yponomeuta evonymella, Operophthera brumata czy Cameraria ohridella. Entomofagi $\mathrm{z}$ rodzaju Liotryphon obniżają liczebność szkodników z rzędu Lepidoptera i Coleoptera, m.in.: Biston betularia, Cydia pomonella, Synanthedon myopaeformis i Saperda populnea. Parazytoidy z rodzaju Scambus również w znaczącym stopniu potrafią ograniczać liczebność: A. rosana, M. neustria i E. chrysorrhoea, ale także Ardis brunniventris i Balaninus glandium. Natomiast Dolichomitus pterelas (Say) może ograniczać liczebność m.in. Zeuzera pyrina (Piekarska-Boniecka 2005).

W 2007 roku nie odnotowano wyraźnego maksimum odłowów gatunków owadów $\mathrm{z}$ rodziny Ichneumonidae (rys. 2). W roku następnym przypadło ono na II dekadę lipca. W ostatnim roku badań najwięcej gąsienicznikowatych odłowiono w II dekadzie maja, II dekadzie czerwca oraz w I dekadzie lipca (rys. 2).

Tereny zieleni miejskiej są miejscem chętnie odwiedzanym i zasiedlanym przez parazytoidy $\mathrm{z}$ rodziny Ichneumonidae. Dowodzi temu fakt, że wszystkie odłowione w latach 2007-2009 gatunki gąsienicznikowatych, z wyjątkiem Dolichomitus pterelas, były już wcześniej wykazywane z tych środowisk przez Sawoniewicza (1986), PiekarskąBoniecką (2004) oraz Piekarską-Boniecką i wsp. (2009a, b). Gatunek $D$. pterelas został stwierdzony po raz pierwszy

Rok 2007 - Year 2007 囚 Rok 2008 - Year $2008 \quad$ Rok 2009 - Year 2009

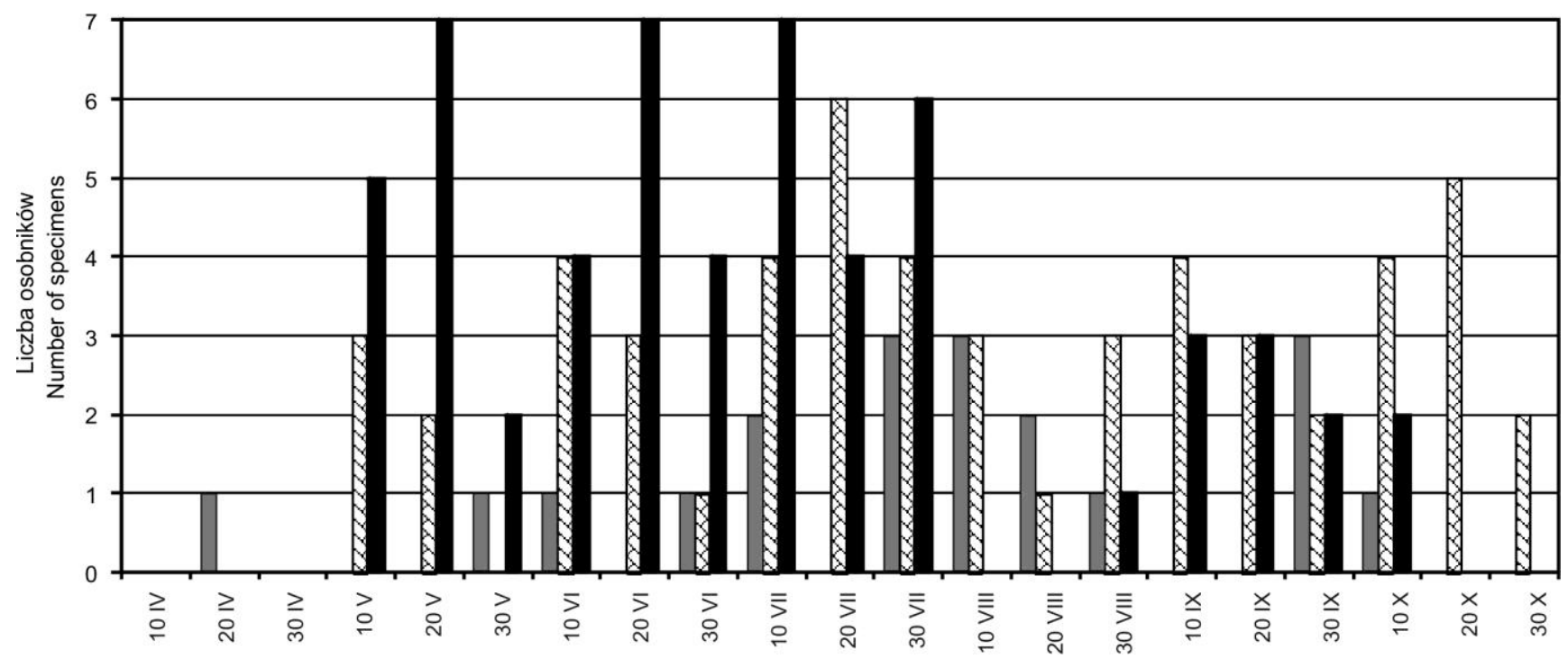

Rys. 2. Dynamika pojawu gatunków z rodziny Ichneumonidae w Ogrodzie Botanicznym Uniwersytetu Adama Mickiewicza w Poznaniu, w latach 2007-2009

Fig. 2. The occurrence dynamics of species of Ichneumonidae family in Adam Mickiewicz University Botanical Garden in Poznań, 2007-2009 
na terenie Wielkopolski. Badania potwierdziły także dominację P. contemplator oraz I. maculator. Gatunki te zostały również wcześniej wykazane jako najliczniejsze w terenach zieleni miasta Poznania (Piekarska-Boniecka 2004; Piekarska-Boniecka i wsp. 2009a).

Parazytoidy $\mathrm{z}$ rodziny Ichneumonidae mogą pełnić ważną rolę $\mathrm{w}$ regulacji liczebności szkodników roślin. Potrafią utrzymać na niskim poziomie najgroźniejsze dla roślin fitofagi $\mathrm{z}$ wielu rzędów. Ograniczają liczebność zarówno szkodników drzew parkowych liściastych i iglastych, ale także krzewów i roślin zielnych. Pozytywny wpływ parazytoidów błonkoskrzydłych na ograniczanie liczebności roślinożerców oraz utrzymanie homeostazy w środowisku miejskim użytkowanym i urządzanym przez człowieka podkreślił Olszak (2010).

Tomalak $(2003,2006)$ stwierdził, że rola ochrony roślin w parkach i lasach miejskich powinna polegać na skutecznym ograniczaniu występowania najważniejszych szkodników drzew i krzewów, z zachowaniem absolutnego bezpieczeństwa mieszkańców. Parazytoidy $\mathrm{z}$ rodziny Ichneumonidae zasiedlające zieleń miejską, odgrywają niezastąpioną rolę, przyczyniając się do poprawy stanu zdrowotnego i estetycznego miejskich założeń parkowych i leśnych.

\section{Wnioski / Conclusions}

1. Na terenie Ogrodu Botanicznego należącego do Uniwersytetu im. Adama Mickiewicza w Poznaniu występują gąsienicznikowate należące przede wszystkim do podrodziny Pimplinae oraz do podrodzin Poemeniinae i Rhyssinae.

2. Parazytoidy preferują jednoroczne i wieloletnie rośliny ozdobne, które zwabiają owady swoją barwą oraz uwalnianiem soków i nektarów stanowiących źródło ich pożywienia.

3. Gąsienicznikowate mogą ograniczać liczebność szkodników występujących w terenach zieleni miejskiej, ponieważ przeważająca liczba gatunków, stwierdzonych na terenie Ogrodu Botanicznego, należała do parazytoidów fitofagów.

\section{Literatura / References}

Bałazy S., Michalski J., Sawoniewicz J. 1979. Badania nad fauną ksylofagów Wielkopolskiego Parku Narodowego, III: Ichneumonidae (Hymenoptera). Badania Fizjograficzne nad Polską Zachodnią XXXIII, Seria C, 32: 69-79.

Bałazy S., Michalski J. 1983. Wstępna charakterystyka entomofauny drewna i środowiska podkorowego drzew w Wielkopolskim Parku Narodowym. Folia Forestalia Polonica, Seria A, 25: 163-184.

Bogdanowicz W., Chudzicka E., Pilipiuk I., Skibińska E. 2007. Fauna Polski - charakterystyka i wykaz gatunków. Tom 2. Muzeum i Instytut Zoologii PAN, Warszawa, 505 ss.

Georgiev G. 2000. Studies on larval parasitoids of Paranthrene tabaniformis (Rott.) (Lepidoptera: Sesiidae) on urban poplars (Populus spp.) in Sofia, Bulgaria. Annals of Forest Science 57: 181-186.

Kaźmierczak T. 2010. Gąsienicznikowate (Hymenoptera, Ichneumonidae) - ich budowa i życie. DRUKPOL, Kraków, 190 ss.

Kaźmierczakowa R., Kaźmierczak T., Kosior A. 1997. Kwiecistość łąk Pienińskiego Parku Narodowego i jej związek z fauną trzmielowatych (Bombini) i gąsienicznikowatych (Ichneumonidae). Ochrona Przyrody 54: 27-58.

Minami T., Ishii M., Temma K. 1999. Difference in parasitoid complex of gypsy moth, Lymantria dispar L. (Lepidoptera: Lymantriidae), between mountain coppice and urban greenery in Osaka, Japan. Japanese Journal of Applied Entomology and Zoology 43 (4): $169-174$.

Olszak R.W. 2010. Rola parazytoidów błonkoskrzydłych w regulacji liczebności roślinożerców. [The importance of hymenopteran parasitoids in limitation of phytophagous insects]. Progress in Plant Protection/Postępy w Ochronie Roślin 50 (3): 1095-1102.

Piekarska-Boniecka H. 2004. Pimplinae, Diacritinae i Poemeniinae (Hymenoptera, Ichneumonidae) terenów zieleni miasta Poznania. s. 179-186. W: „Fauna miast Europy Środkowej 21. wieku” (P. Indykiewicz, T. Barczak, red.). LOGO, Bydgoszcz, 580 ss.

Piekarska-Boniecka H. 2005. Dynamika zgrupowań Pimplinae (Hymenoptera, Ichneumonidae) w krajobrazie rolniczym środkowej Wielkopolski. Roczniki Akademii Rolniczej w Poznaniu, Rozprawy Naukowe 366, 204 ss.

Piekarska-Boniecka H., Trzciński P., Dolańska-Niedbała E. 2009a. Parazytoidy (Hymenoptera, Ichneumonidae) występujące w Ogrodzie Botanicznym UAM w Poznaniu. [Parasitoids (Hymenoptera, Ichneumonidae) occurring in the Botanical Garden of Adam Mickiewicz University in Poznań]. Progress in Plant Protection/Postępy w Ochronie Roślin 49 (2): 874-877.

Piekarska-Boniecka H., Ratajczak J., Dolańska-Niedbała E. 2009b. Parasitic wasps of the Pimplinae, Poemeniinae and Diacritinae (Hymenoptera, Ichneumonidae) subfamilies at Kórnik Arboretum. Folia Horticulturae 21 (1): 119-127.

Sawoniewicz J. 1982. Ichneumonidae (Hymenoptera) of Warsaw and Mazovia. Memorabilia Zoologica 36: 5-39.

Sawoniewicz J. 1986. Structure of Ichneumonidae (Hymenoptera) communities in urban green areas of Warsaw. Memorabilia Zoologica 41: 103-124.

Szulczewski J. 1939. Błonkówki (Hymenoptera). Cz. II. Gąsieniczniki (Ichneumonidae). Prace Monograficzne nad Przyrodą Wielkopolskiego Parku Narodowego, Poznań, 28 ss.

Tomalak M. 2003. Najważniejsze problemy ochrony drzew miejskich przed szkodnikami. [Most important issues in protection of urban trees against pest insects]. Progress in Plant Protection/Postępy w Ochronie Roślin 43 (1): 427-435.

Tomalak M. 2006. Postrzeganie drzew, szkodników oraz zabiegów ochrony roślin na obszarach parków i lasów miejskich. [Citizen's perceptron of trees, tree pests and pest management - related activity in urban parks and forests]. Progress in Plant Protection/Postępy w Ochronie Roślin 46 (1): 337-343.

Yu D.S., Horstmann K. 1997. A catalogue of world Ichneumonidae (Hymenoptera). Part 1 and 2. Memoirs of the American Entomological Institute 58.

Yu D.S. 2012. Interactive catalogue of world Ichneumonidae. Taxapad. http://www.taxapad.com/ [Accessed: 01.12.2014]. 